\title{
Vital Events Registration as an Effective Tool to Monitor Social Security Cash Transfer in Nepalese Context
}

\author{
${ }^{1}$ Mahesh Maharjan, and ${ }^{2}$ Subarna Shakya \\ ${ }^{1}$ Department of Computer Science and Engineering, Singhania University, Rajasthan, India \\ ${ }^{2}$ Department of Electronics and Computer Engineering, Central Campus, Institute of Engineering, Tribhuvan \\ University, Pulchowk, Lalitpur, Nepal
}

\begin{abstract}
To a person, different events like birth, marriage, migration, divorce and death occur from time to time. These vital events are found to be well organized and managed for different purpose. For monitoring social security cash transfer, census study, local and national level planning, these events are organized to address these issues by respective government. The government of Nepal has been spending huge amount of money in social security allowance and maintaining database of beneficiaries through manual process in hard copy. The research is concerned with social cash transfer through the use of electronic database and ICT tools with direct linkage with vital events registration. The researcher has used online and hard copy tools to gather primary data from local and central level. Moreover, the researcher's field level experiences have also been used. The preliminary finding of research is that that online vital events registration process monitors social security cash transfer effectively and efficiently.It helps government for short and long term planning, and for development through tremendous use of ICT.
\end{abstract}

Keywords: Vital events, Social cash transfer, ICT, Development and Planning

\section{Introduction}

The Government of Nepal has been providing different types of social security allowances like senior citizens allowance, window allowance, fully disabled allowance, etc to its target groups since 1994/95 A.D. The number of beneficiaries has been increasing annually. Thedetail information of those beneficiaries needs to be stored, managed and reported by the government to distribute their cash effectively and efficiently. In order to make social security cash transfer more effective, use of proper electronic database and ICT tools plays significant role. Since, the beneficiaries list is prepared and finalized at local level; it is aresponsibility of local government itself to distribute social cash transfer to the beneficiaries without any hassles. Moreover, the central government that transfers total amount requested by the local level is also equally responsible. The representatives from central level should manage, monitor, control and evaluate social security cash transfer at certain time interval.

Through local and national news, media and newspaper, we see and hear that social security cash transfer is being carried out by few and less experience staff. The final report should be transparent with proper public audit process. It means that there are problems in social security cash transfer, problems like ghost beneficiaries, payment on name of death, over age and under age people and so on. So, as to monitor and control the social security cash transfer, there is need of centralized and updated database of social security beneficiaries. It is a natural phenomenon that a child gets birth, grows up with lots of enjoyment and sorrows and finally dies. The process of recording full life cycle events like birth, marriage, migration, divorce and death of the child is known as vital events registration or civil registration. Each born child has right to have birth registration at registration office where event has occurred. These vital events have been recorded at local registration office in hard copy with manual process. The vital events records are very much important and critical to citizen and government also. These events play significant roles in many areas like monitoring social security cash transfer, census study, local and national level planning and so on.

The vital events registration has direct linkage with social security cash transfer. Few linkages between vital events and social security cash transfer have been bulleted as below: 
1. Once a child birth registration is done, if the child is under the target group, the name of a child needs to be added into the list of social security beneficiaries for next fiscal year.

2. Suppose one senior citizen allowance beneficiary's death registration is done, it reflects at two different areas. First the death person name list needs to be removed from the current social security beneficiaries list. Next, if the death one is married then his wife(s) name needs to be automatically added into the social security beneficiaries list.

3. The official representative can easily forecast budget for social security cash transfer for next fiscal year or after certain number of years.

Therefore, through the use of electronic database and ICT tools, vital events registration could be an effective tool to monitor social security cash transfer. It also helps government through short and long term planning and for development process.

\section{Methods}

The research article is based on primary and secondary sources of information. The researcher has collected primary data through online and hard printed copy tools from grass root to policy level. The research's experiences have also been used. Moreover, related books, articles, publications and research papers are also used.

\section{Literature Review}

ICT has transformed the way in which people live, work and spend their money. Public sector organizations have focused their efforts towards digitalizing their services to their customers or citizens through the Internet so that users can easily use the available services from any place and at any time [1]. Developing countries have been using IT and ICT as potentially useful tools for social improvements as well as to improve efficiency of government services. Nepal is also extending its services to communicate with poor people and mountain regions [2]. The use of ICTs increases the performance of social security agencies; improve the quality of social security tools and also the delivery mechanism of social security programmes and services [3].

Social security refers to government programmes that intend to promote the welfare of citizens through assistance measures, guaranteeing access to sufficient resources for food and shelter. Primarily it is directed towards potentially vulnerable population of the country such as children, the elderly, the sick and the unemployed [4]. Social security system assures the right of socially, economically, physically and psychologically vulnerable people for normal and dignified life [5]. Basically, there are four reasons the government is concerned on social security, namely fight against poverty and its vulnerability, need for an improved consumption smoothing, improved equity in the society and risk management on economic development. The social security provide by the state may be a direct transfer, in-kind or in-cash [6].

The government of Nepal has been spending more than $3 \%$ of the total budget for social security cash transfer. It is being handled by limited human resources. The local bodies are not enthusiastic in implementing the programmes due to lack of administrative expenses and limited human resources. Quality service delivery has still not been achieved, though there is an increment in the volume of allocation to the social security programmes. The inter-bodies coordination system is very weak. Implementation of the social security programmes is scattered among various agencies, so some tend to benefit twice while some are left out of the programmes. Social security programmes are not monitored effectively. There is difficulty in getting an updated statement, so there are problems in the VDCs, municipalities, DDCs and the ministry itself[6].

Pressure on the budget is high and is increasing each year. Determining how much the target groups are actually benefitting is still a challenge. As the social security programme is highly popular, political influence and pressure are common and widely accepted. Sectoral ministries and central concerned agencies are not connected with the Management Information System. The dependency syndrome has been increasing [6]. There is no sufficient information regarding e-Government implementation at the local level as e-Government researches have focused on national and state-level with few investigations focused on the local government [7]. 
TABLE I: Target group wise no of social security allowance beneficiaries(Adopted from [8])

\begin{tabular}{|c|c|c|c|c|c|c|}
\hline \multirow{3}{*}{ S.N } & \multirow{3}{*}{ Target Group } & \multirow{3}{*}{$\begin{array}{l}\text { Monthly } \\
\text { Rate (Rs) }\end{array}$} & \multicolumn{4}{|c|}{ Fiscal Year } \\
\hline & & & $2011 / 12$ & $2012 / 13$ & $2013 / 14$ & $2014 / 15$ \\
\hline & & & $\begin{array}{c}\text { No of } \\
\text { Beneficiaries }\end{array}$ & $\begin{array}{c}\text { No of } \\
\text { Beneficiaries }\end{array}$ & $\begin{array}{c}\text { No of } \\
\text { Beneficiaries }\end{array}$ & $\begin{array}{c}\text { No of } \\
\text { Beneficiaries }\end{array}$ \\
\hline 1 & Senior Citizens (Others) & 500 & 635938 & 605021 & 663693 & 655777 \\
\hline 2 & Senior Citizens (Dalit) & 500 & 125819 & 130917 & 170825 & 238207 \\
\hline 3 & Senior Citizens (Karnali) & 500 & 30758 & 14056 & 29626 & 28757 \\
\hline 4 & Single Women & 500 & 319781 & 258113 & 361350 & 341106 \\
\hline 5 & Widow & 500 & & 536312 & 219933 & 313613 \\
\hline 6 & Fully Disabled & 1000 & 16202 & 18252 & 22138 & 25492 \\
\hline 7 & Partial Disabled & 300 & 6850 & 6875 & 6774 & 6863 \\
\hline 8 & $\begin{array}{l}\text { Endangered / Indigenous } \\
\text { Ethnicity }\end{array}$ & 1000 & 19681 & 19299 & 18828 & 19223 \\
\hline 9 & Children & 200 & 409105 & 458135 & 551916 & 537118 \\
\hline & Total & & 1564134 & 2046980 & 2045183 & 2166156 \\
\hline
\end{tabular}

The developing countries have weak national identification (ID) and vital registration systems. The weaknesses in these systems can lead to two major issues in the provision of social security allowances and services. First, identification problems can result in exclusion from much-needed social securityprogrammes, as eligible people are sometimes not able to register for government programmes. Next, the less capacity of governments to verify identities can also result in massive leakages. In both cases, weak systems can lead to undesirable outcomes for well-designed programmes [9].

Information System researchers are usually keen to investigate what happens when a new IT product is used in a real-life context by real people, and software engineering researchers are also becoming increasingly interested in empirical research into the real-world use of their IT products [10].

A vital event registration is auniversal, continuous, permanent and compulsory recording of the occurrence like birth, death, marriage, etc [11]. It is a legal document and very much useful as a source of statistics for health planning and socio- economic development. It affects in the individual or family and the community or country. For the individual or family, the civil registration provides legal evidence of the birth which is necessary for proof of age, identity card, school admission, etc; and, legal evidence of death which is necessary for insurance claims, succession rights to property, family allowance, etc [12]. For administration of a public activity, it requires some form of registration. Since the work of the public administration mainly involves dealing with people, it is necessary to be able to identify such persons and gain access to general personal data like name, address, age, marital status, etc [13].

There are three main reasons for the development of a good vital event registration system. They are as follows:

1) The legal or evidentiary value of a registration record to the individual.

2) The use in public health programmes.

3) The value in socio-economic and demographic planning.

Over the past decade in both developed and developing countries, the electronic and automatic process of vital events has been addressed several times [14]. In those countries which do not have centralized, computerized registration, the public authorities have to request the citizens to provide the same data time and again. As a result, the data collected by different authorities is not only of poor quality, often it is not identical.The establishment of a centralized civil registration system is thus the basis for the creation of a 
streamlined and rational administrative infrastructure. This enables the public authorities to give the citizens the best possible service[13].

At different levels such as VDC, ward office, hospital, etc from where vital events registration process is carried out, databases and spreadsheets can be used to collect, compile, transmit, validate, store and analyse data [15]. The use of information and communication technology, including mobile technology, is facilitating the registration of vital events in remote, isolated, and mountainous areas [16]. The use of advancements in technology and their application needs to be used to makethe vital events automatic through several phases. In the first phase of the automation process, the national government runs a registration programme as a campaign under legal mandate to have an effective means to administer and operate the programme.Then, establishing database, the preparation of record copies and reports, and the compilation of related statistics needs to be done. They become much more efficient and economical than in existing manual systems [14].The use of ICT has also delivered benefits in data transfer, with internet and wireless technologies significantly shortening the time needed to transfer micro data and aggregated data [15].

Through the increasing use of relatively inexpensive ICT, many countries have fully computerized the registration system at all levels, which greatly facilitated the managing and maintaining the system. It has been helping to solve many issues. The use of ICT can also speed up the compilation and availability of vital statistics [15]. The utility and effectiveness of automation in terms of costs, operational productivity and timely system responsiveness are major reasons for redirecting programmes to an automated environment. This approach gives immediate benefits in reducing workload and processing [14]. Cross-matching and linking with other systems is one of the important advantages of electronic records. Electronic record linkage enables large numbers of records to be linked and scanned, and has proved to be a valuable tool for improving the ascertainment of causes of death[9].

The vital events registration helps to produce reliable and complete vital statistics which supports national and local decision-making and planning across a range of social and economic sectors [16]. Vital statistics is essential for planning and providing the numerical profile of the nation [11].

\section{Result and Discussion}

The primary data have been collected from six districts of Nepal namely Dang, Rupendhi, Kailali, Illam, Rautahat and Kanchapur. The researcher has collected data from 120 research participants from VDC staff (Dang - 35, Illam - 21, Rupendehi - 29, Rautahat -7,Kanchanpur - 4 and Kailali - 24). The collected data have been properly coded and entered into SPSS package for data analysis. And at policy level, primary data have been collected from director of social security section of Department of Civil Registration (DoCR).

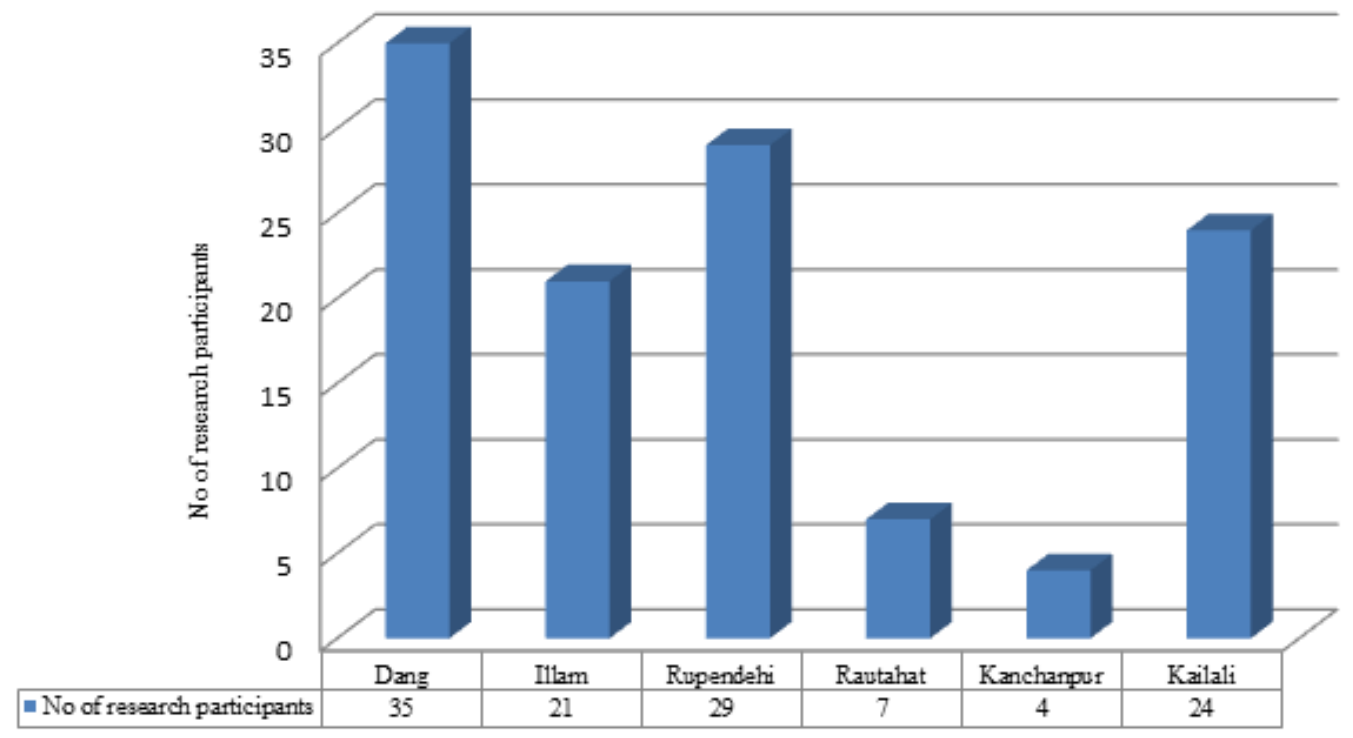

Fig 1: District wise no of research participants 


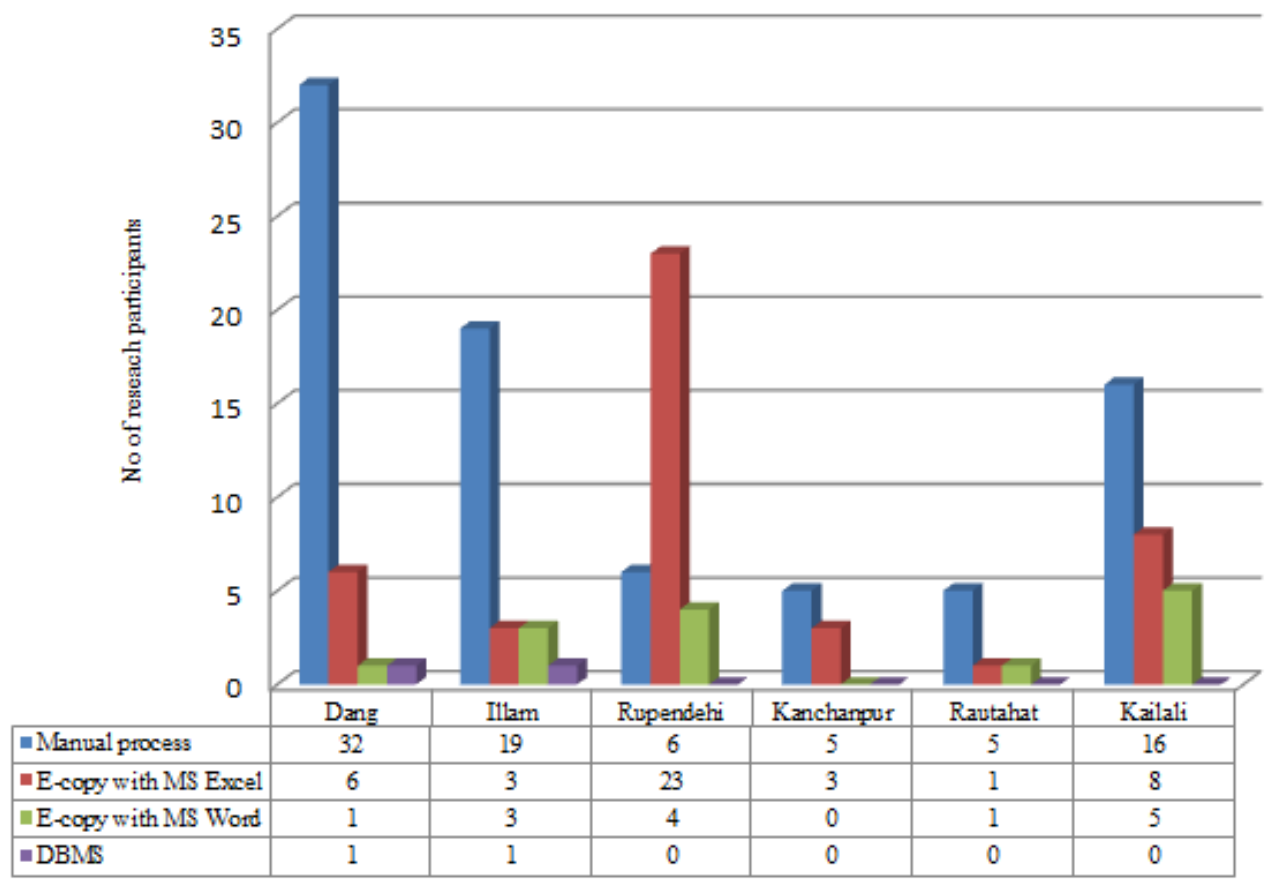

Fig 2: District wise status of social security beneficiaries' data

It has been found that in 58\% of VDC offices, social security beneficiaries' data have been maintained in register through manual process, 31\% in E-copy with Excel, 10\% in E-copy with MS Word and 1\% using database.Similarly, $41 \%$ of research participants shared that there has been problems on updating data of beneficiaries' because of non registration of death beneficiaries, 34\% because of non- reporting from migrant households and $25 \%$ because of age misreporting. All these problems are directly linked with vital events registration. Moreover, the director of social security section has also shared that updating social security beneficiaries' lists is difficult as information of death beneficiaries; migrated people and over age child have not been updated on time. There should be direct linkage of social security programme with vital events registration.

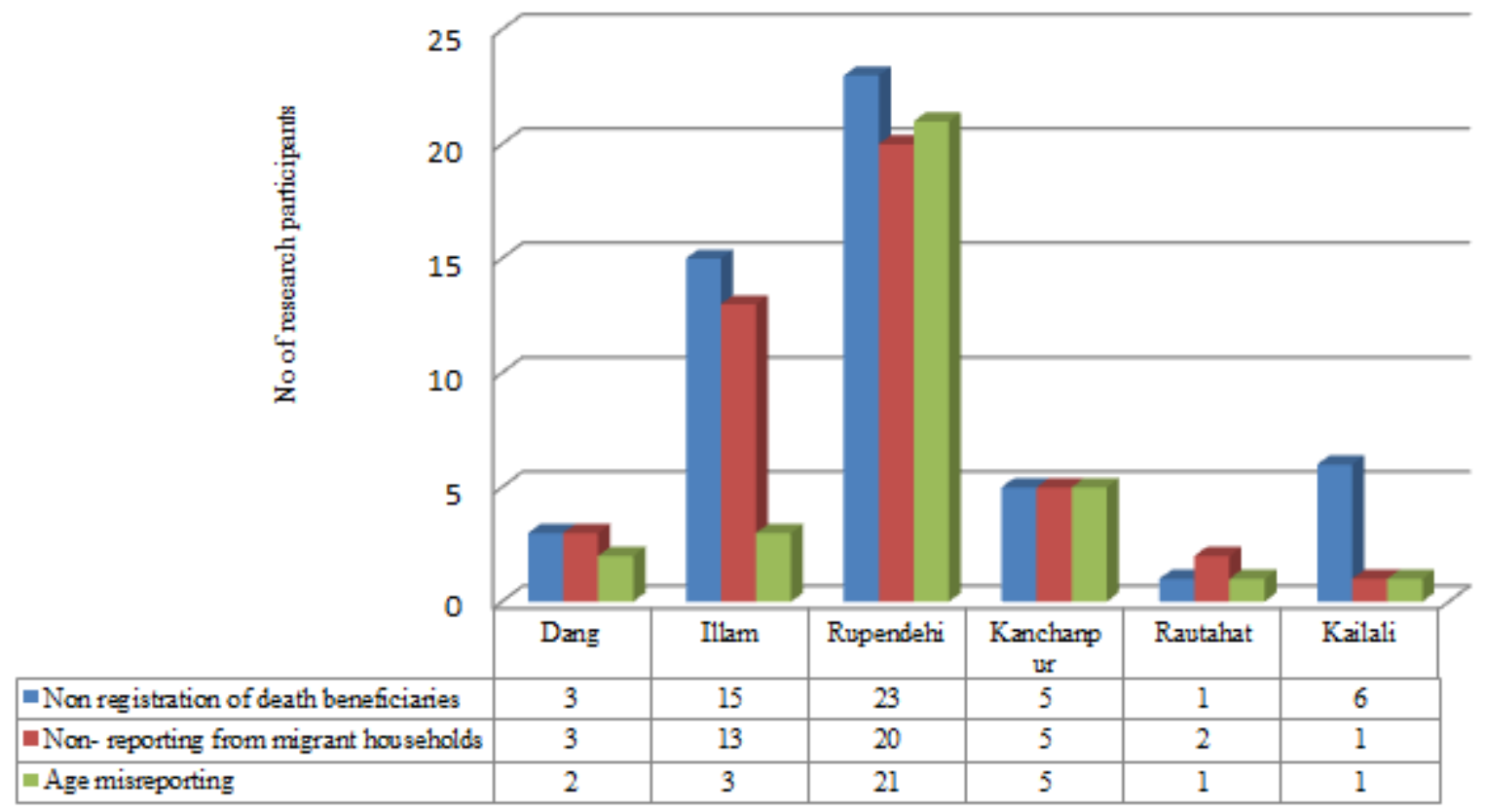

Fig 3: District wise problems on updating social security beneficiaries' data 


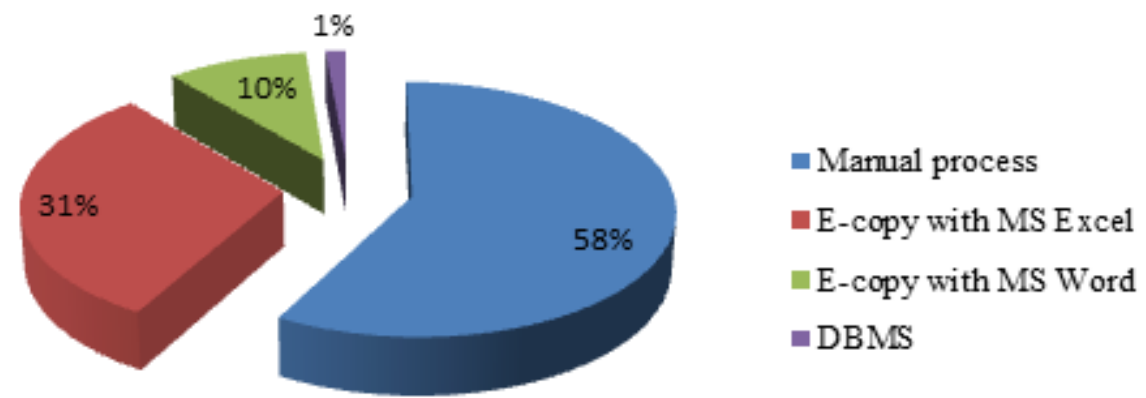

Fig 4: Status of social security beneficiaries' data

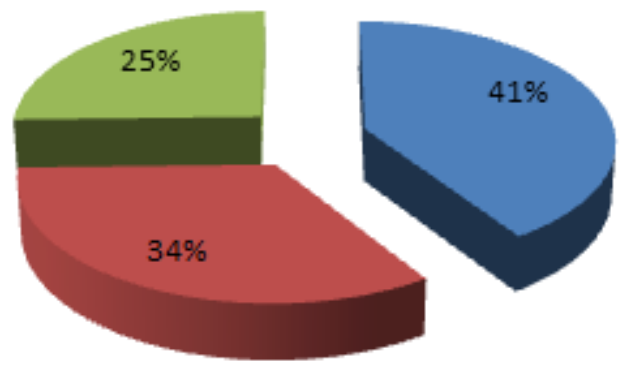

\author{
Non registration of death \\ beneficiaries \\ Non- reporting from \\ migrant households \\ - Age misreporting
}

Fig 5: Status of problems on updating social security beneficiaries' data

From the above result it shows that there should be direct linkage between vital events registration and social security cash transfer. The vital events registration is very much essential and important process to monitor social security cash transfer. To make the social security cash transfer more effective and efficient, an electronic centralized database and ICT tools play significant role.

\title{
5. Conclusion
}

The government of Nepal has been distributing social security cash transfer since two decade on a manual basis without direct linkage with vital events registration. Through vital events registration, social security cash transfer should be maintained and control. The government should start the process of digitizing vital events registration and social security cash transfer programme through a single centralized database. A common unique ID of each citizen that is generated at the time of birth registration is highly necessary to make social security cash transfer more effective and realistic. Besides, a common centralized database should be shared across different ministries and departments like National ID Management Center, Ministry of Health and Population, Ministry of Home Affairs, Ministry of Education, etc for different types of short and long term planning of a nation. Finally, a well centralized data centre with proper data recovery site should be well established so as to maintain and control social security cash transfer and use of spending such a huge amount of government money towards the public. Since, the ICT infrastructure at local level is not sufficient, the research recommends the process of digitizing and online registration of vital events and social security in a cluster basis like a common centre point for neighborhoods VDC offices.

\section{References}

[1] P. Upadhyaya, S. Shakya, and M. Pokharel, "Information Security Framework for E-Government Implementation in Nepal", Journal of Emerging Trends in Computing and Information Sciences, vol. 3, no. 7, July 2012, ISSN 2079 8407.

[2] L. Burton, The Development of Nepal's IT policy, IDRC, 2003.

[3] S. Sahu, Mainstreaming Information and Communication Technology (ICT) for social protection challenges and opportunities in Asia and the Pacific, 2011. 
[4] P. Mathema, National social security policy: A reality for Nepal. Administrative and Management Review, vol 24, no 2, August 2012.

[5] C. R. Uprety, Ageing and Social Security System in Nepal: Scope and Challenges. Tribhuvan University, Kathmandu, Nepal, 2006.

[6] National Planning Commission, Assessment of Social Security Allowance Program in Nepal. Kathmandu, Nepal, 2012.

[7] R. Nabafu and G. Maiga, Towards a Model for Implementing Local E-government in Uganda, n.d.

[8] Ministry of Federal Affairs and Local Development (MoFALD), Annual progress report 2012/13, Kathmandu: Nepal Government Printing Office, Singhadurbar, 2013, pp. 38.

[9] Social Protection and Labor, Building Robust Identification Systems, 2014.

[10] B.J. Oates, Researching Information Systems and Computing, New Delhi: Sage Publications, 2007, pp. 109, 111.

[11] United Nations Statistics Division, Importance and Services of Civil Registration and Vital Statistics Systems, 2010.

[12] A.S. AI-Rabie,Registration of Vital Events in Iraq, International Institute for Vital Registration and Statistics, USA, 1980.

[13] C. Malig, The Civil Registration System in Denmark, International Institute for Vital Registration and Statistics, USA, 1996.

[14] V.M. Logrillo, Role of Technology in the Civil Registration Process, International Institute for Vital Registration and Statistics, USA, 1997.

[15] WHO, Strengthening civil registration and vital statistics for births, deaths and causes of death resource kit, 2013.

[16] Government of Liberia, Civil Registration and Vital Statistics Assessment, n.d. 